\title{
AKOMODASI BUDAYA LOKAL DALAM PUTUSAN TARJIH MUHAMMADIYAH
}

\author{
Supardi Mursalin \\ Fakultas Syariah IAIN Bengkulu \\ Jl. Raden Fatah Pagar Dewa Bengkulu \\ Email: supardimursalin@yahoo.com
}

\begin{abstract}
The cultural appreciation in Muhammadiyah seemed to be unfavorable. Muhammadiyah residents are considered to have anti-cultural tendencies, and in reality Muhammadiyah is known as a missionary movement that is very anti against popular religious cultures such as tahlilan, yasinan, and istighasah. This impression is not entirely true, because one of the institutions in Muhammadiyah, Majelis Tarjih and Tajdid, discussed religious issues that emerged in the community to find solutions, solutions or answers. The issue of the Veil in the Tarjih Muhammadiyah Decision has somewhat revealed a desire to accommodate local culture with the verdict applied. This accommodation, textually the verdict is considered still shy, but in the field in general it has adjusted to the local culture or even with the progress of civilization.
\end{abstract}

Keywords: local culture, tarjih verdict, Muhammadiyah

Abstrak: Apresiasi budaya dalam Muhammadiyah terkesan kurang baik. Warga Muhammadiyah dianggap memiliki kecenderungan anti budaya, dan dalam realitasnya Muhammadiyah dikenal sebagai gerakan dakwah yang sangat anti terhadap budaya agama yang populer seperti tahlilan, yasinan, dan istighasah. Kesan seperti ini tidak sepenuhnya benar, karena salah satu lembaga dalam Muhammadiyah, Majelis Tarjih dan Tajdid, membahas masalah keagamaan yang muncul di masyarakat untuk dicarikan solusi, jalan keluar ataupun jawabannya. Permasalahan tentang Tabir dalam Putusan Tarjih Muhammadiyah sedikit banyaknya sudah menampakkan keinginan usaha mengakomodasi budaya lokal dengan putusan yang diterapkan. Akomodasi ini, secara tekstual putusan tersebut dinilai masih malu-malu, akan tetapi di lapangan secara umum sudah menyesuaikan dengan budaya setempat atau bahkan dengan kemajuan peradaban.

Kata kunci: budaya lokal, putusan tarjih, Muhammadiyah

\section{Pendahuluan}

Muhammadiyah sebagai salah satu organisasi sosial keagamaan di tanah air telah memasuki abad kedua. Perhitungan ini didasarkan pada kalender Qamariyah. Muhammadiyah didirikan KH. Ahmad Dahlan di Yogyakarta pada 18 Dzulhijjah 1330 H/18 November 1912. ${ }^{1}$ Salah satu tantangan yang dihadapi Muhammadiyah ketika memasuki abad kedua adalah menemukan formulasi yang tepat untuk mengurai hubungan agama dan budaya. Permasalahan hubungan agama dan budaya ini merupakan persoalan yang telah dibicarakan Muhammadiyah dalam beberapa diskusi, seminar, dan even resmi organisasi seperti sidang Tanwir dan Muktamar.

${ }^{1}$ Haedar Nashir, dkk, Materi Induk Pengkaderan Muhammadiyah, (Yogyakarta: BPK Pimpinan Pusat Muhammadiyah, 1994), h. 124.
Ketika membicarakan kiprah Muhammadiyah dalam mengapresiasi budaya biasanya dijumpai pandangan yang agak miring. Kuntowijoyo, misalnya, mengingatkan agar warga Muhammadiyah tidak memiliki kecenderungan anti budaya, sebab untuk kembali kepada paradigma Alquran dan sunah (al-ruju' ila al-Qur'an wa alSunnah) dan sikap kehati-hatiannya cenderung seperti gerakan anti kebudayaan. ${ }^{2}$ Selanjutnya, dalam realitasnya Muhammadiyah dikenal sebagai gerakan dakwah yang sangat anti terhadap budaya agama yang populer seperti tablilan, yasinan, dan istighasah.

Salah satu lembaga otonom dalam Muham-

${ }^{2}$ Kuntowijoyo, Muslim Tanpa Masjid: Esai-esai Agama, Budaya, dan Politik dalam Bingkai Strukturalisme ransendental, (Bandung: Mizan, 2001), h. 158. 
madiyah adalah Majelis Tarjih dan Tajdid Muhammadiyah (MTT), yang dalam tulisan ini disingkat menjadi Majelis Tarjih. Lembaga ini membahas masalah keagamaan yang muncul di masyarakat untuk dicarikan solusi, jalan keluar ataupun jawabannya.

Artikel ini akan melihat salah satu putusan Majelis Tarjih tentang Tabir atau Hijab dalam pertemuan antara laki-laki dan perempuan, hubungannya dengan akomodasi budaya lokal.

\section{Majelis Tarjih Muhammadiyah}

Majlis Tarjih Muhammadiyah didirikan atas dasar keputusan Kongres Muhammadiyah keXVI pada tahun 1927 di Pekalongan, atas usul K.H. Mas Mansyur. Fungsi dari majlis ini adalah mengeluarkan fatwa atau memastikan hukum tentang masalah-masalah tertentu. Masalah itu tidak semata-mata terletak pada bidang agama dalam arti sempit, tetapi mungkin juga terletak pada masalah bidang agama yang didasarkan atas dalil syariah, yaitu Alquran dan hadis. Proses pengambilan hukum dalam majelis ini didasarkan pada ilmu usul fikih. Majlis ini berusaha untuk mengembalikan suatu persoalan kepada sumbernya, yaitu Alquran dan hadis, baik masalah itu semula sudah ada hukummnya dan berjalan di masyarakat tetapi masih dipertikaikan di kalangan umat Islam, atau pun yang merupakan masalahmasalah baru, yang sejak semula memang belum ada ketentuan hukumnya, seperti masalah keluarga berencana, bayi tabung, bank dan lain-lain.

Tarjih adalah suatu metode atau cara untuk menyelesaikan dua atau lebih dalil yang saling berbeda atau bertentangan. Ahli usul fikih mendefinisikan tarjih sebagai membandingkan dua dalil yang bertentangan dan mengambil yang terkuat di antara keduanya. Kedua dalil yang bertentangan itu memiliki kedudukan yang sama yaitu sama-sama zhanni. Dalam membahas dalildalil yang ada, para mujtahid berbeda satu dengan yang lainnya karena adanya dua atau lebih dalil yang muncul, yang kedudukan dalil-dalil tersebut sama-sama zhanni, maka untuk menyelesaikan pertentangan itu diadakanlah tarjih.

\section{Tabir antara Tempat Laki-Laki dengan Tempat Wanita}

Para ulama berbeda pandangan tentang kewajiban memasang tabir antara tempat lakilaki dengan tempat wanita. Mereka sepakat bahwa para wanita wajib menutup aurat dan berpakaian sesuai dengan ketentuan syari'at, tidak boleh terjadi ikhtilat (campur baur) antara laki dan wanita. Selanjutnya, haramnya khalwat atau berduaan menyepi antara laki-laki dan wanita.

Sedangkan kewajiban untuk memasang kain tabir penutup antara ruangan laki-laki dan wanita, sebagian ulama mewajibkannya dan sebagian lainnya tidak mewajibkannya.

Para ulama yang mewajibkan dipasangnya kain tabir penutup ruangan berangkat dari dalil Alquran dan sunah.

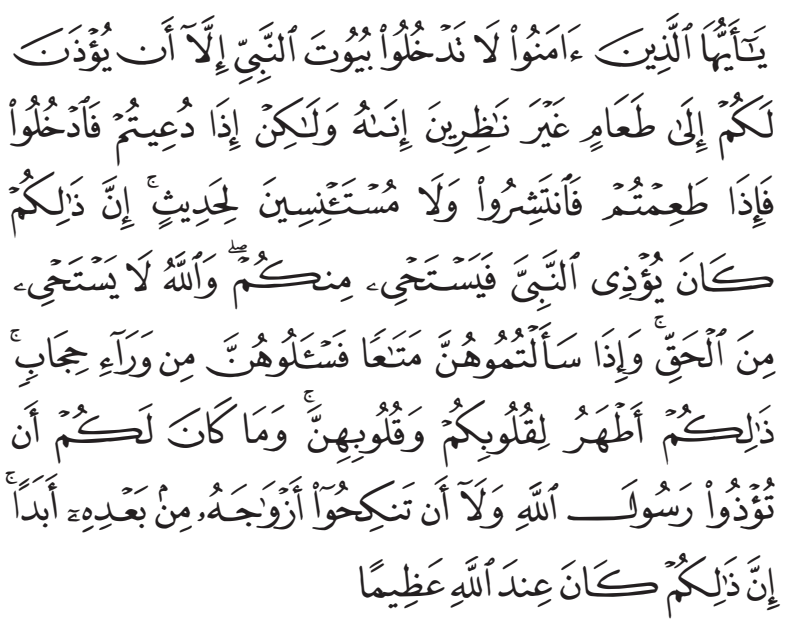

"Hai orang-orang yang beriman, janganlah kamu memasuki rumah-rumah Nabi kecuali bila kamu diizinkan untuk makan dengan tidak menunggununggu waktu masak, tetapi jika kamu diundang maka masuklah dan bila kamu selesai makan, keluarlah kamu tanpa asyik memperpanjang percakapan. Sesungguhnya yang demikian itu akan mengganggu Nabi lalu Nabi malu kepadamu, dan Allah tidak malu kepada yang benar. Apabila kamu meminta sesuatu kepada mereka, maka mintalah dari belakang tabir. Cara yang demikian itu lebih suci bagi hatimu dan hati mereka. Dan tidak boleh kamu menyakiti Rasulullah dan tidak mengawini isteri-isterinya selama-lamanya sesudah ia wafat. Sesungguhnya perbuatan itu adalah sangat besar di sisi Allah." (QS. Al-Ahzab: 53)

Ayat tersebut menyatakan bahwa memasang 
kain tabir penutup meski perintahnya hanya untuk para isteri Nabi, tapi berlaku juga hukumnya untuk semua wanita. Karena pada dasarnya para wanita harus menjadikan para istri Nabi itu menjadi teladan dalam amaliyah sehari-hari. Sehingga kihtab ini tidak hanya berlaku bagi istriistri Nabi saja tetapi juga semua wanita mukminat.

Diriwayatkan oleh Nabhan bekas hamba Ummu Salamah, bahwa Rasulullah saw pernah berkata kepada Ummu Salamah dan Maimunah yang waktu itu Ibnu Ummi Maktum masuk ke rumahnya. Nabi saw bersabda:

"Pakailah tabir." Kemudian kedua isteri Nabi itu berkata: "Dia (Ibnu Ummi Maktum) itu buta!" Maka jawab Nabi: "Apakah kalau dia buta, kamu juga buta? Bukankah kamu berdua melihatnya?"

Sedangkan ulama yang tidak sependapat mengatakan bahwa tabir penutup ruangan yang memisahkan ruangan laki-laki dan wanita berlaku hanya untuk pada istri Nabi, sebagaimana zahir firman Allah dalam surat Al-Ahzab: 53. Hal itu diperintahkan hanya kepada istri nabi saja karena kemuliaan dan ketinggian derajat mereka serta rasa hormat terhadap para ibu mukminin itu. Sedangkan terhadap wanita mukminat umumnya, tidak menjadi kewajiban. Dan bila mengacu pada asbabun nuzul ayat tersebut, memang kelihatannya diperuntukkan kepada para istri nabi saja.

Selanjutnya, kalangan ahli tahqiq (orangorang yang ahli dalam penyelidikannya terhadap suatu hadis/pendapat) mengatakan bahwa hadis Ibnu Ummi Maktum itu merupakan hadis yang tidak sah menurut ahli-ahli hadis, karena Nabhan yang meriwayatkan Hadis ini salah seorang yang perkataannya tidak dapat diterima. Bila hadis ini sahih, maka sikap kerasnya Nabi kepada isteriisterinya karena kemuliaan mereka, sebagaimana beliau bersikap keras dalam persoalan hijab.

Banyak ulama yang mengatakan bahwa seorang isteri boleh melayani tamu-tamu suaminya di hadapan suami, asal dia melakukan tata kesopanan Islam, baik dalam segi berpakaian, berhias, berbicara dan berjalannya. Sebab secara wajar mereka ingin melihat satu sama lainnya. Oleh sebab itu, tidak berdosa untuk berbuat seperti itu apabila diyakinkan tidak terjadi fitnah suatu apapun baik dari pihak isteri maupun dari pihak tamu.

Sahal bin Saad al-Anshari berkata sebagai berikut:

"Ketika Abu Asid as-Saidi menjadi pengantin, dia mengundang Nabi dan sahabat-sahabatnya, sedang tidak ada yang membuat makanan dan yang menghidangkannya kepada mereka itu kecuali isterinya sendiri, dia menghancurkan (menumbuk) korma dalam suatu tempat yang dibuat dari batu sejak malam hari. Maka setelah Rasulullah saw selesai makan, dia sendiri yang berkemas dan memberinya minum dan menyerahkan minuman itu kepada Nabi." (HR. Bukhari dan Muslim)

Dari hadis ini, Syaikhul Islam Ibnu Hajar berpendapat: "Seorang wanita boleh melayani suaminya sendiri bersama orang laki-laki yang diundangnya...". Tetapi tidak diragukan lagi, bahwa hal ini apabila aman dari segala fitnah serta dijaganya hal-hal yang wajib, seperti hijab. Begitu juga sebaliknya, seorang suami boleh melayani isterinya dan wanita-wanita yang diundang oleh isterinya itu. Dan apabila seorang wanita itu tidak menjaga kewajiban-kewajibannya, misalnya soal hijab, seperti kebanyakan wanita dewasa ini, maka tampaknya (terlihatnya) seorang wanita kepada laki-laki lain menjadi haram.

Pandangan tidak wajibnya tabir didukung pada kenyataan bahwa masjid Nabawi di masa Rasulullah saw masih hidup pun tidak memasang kain tabir penutup yang memisahkan antara ruangan laki-laki dan wanita. Bahkan sebelumnya, mereka keluar masuk dari pintu yang sama, namun setelah jumlah mereka semakin hari semakin banyak, akhirnya Rasulullah saw menetapkan satu pintu khusus untuk para wanita. Hanya saja Rasulullah saw memisahkan posisi shalat laki-laki dan wanita, yaitu laki-laki di depan dan wanita di belakang.

Pada masa Nabi saw tidak ada pembatas (baik dari tembokataukain) di masjid Nabawiatau masjid lainnya, begitu juga pada zaman khulafa' Rasyidin. Nabi saw dan Khulafaurrasyidin belum pernah memerintakan pembuatan pembatas tersebut.

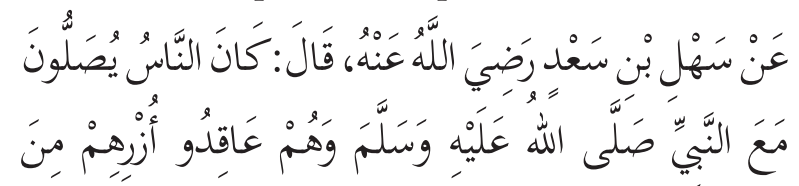




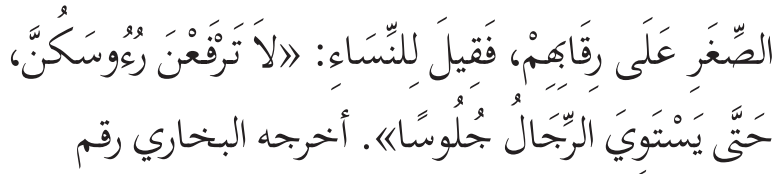

Sabl bin Sa'd ra berkata: dahulu orang-orang shalat dengan Nabi saw dalam keadaan mengikatkan kain-kain mereka di leher disebabkan kecilnya kain tersebut, maka dikatakan kepada kaum wanita janganlah kalian mengangkat kepala kalian sampai para laki-laki duduk.

Hal ini karena ditakutkan kaum wanita melihat aurat laki-laki. Seandainya ada pembatas kain atau yang lainnya niscaya hal tersebut tidak perlu dikhawatirkan dari kaum wanita. Akan tetapi jika dikhawatirkan terjadinya fitnah maka tidak apa mendirikan pembatas antara laki-laki dan perempuan.

\section{Tabir dalam Tarjih Muhammadiyah}

Dalam Himpunan Putusan Tarjih Muhammadiyah, terdapat dua bagian yang membicarakan tentang tabir dalam sidang/rapatrapat Muhammadiyah. Pertama, dalam bagian Kitab beberapa Masalah, dan kedua dalam Keputusan Tarjih Sidoarjo.

Dalam Kitab Beberapa Masalah dengan judul Tabir dalam Sidang dinyatakan bahwa: Oleh karena ketentuan menahan penglihatan itu diperintahkan, sebagaiman firman Allah: "Katakanlah kepada orang-orang mukmin (pria) supaya memejamkan penglihatannya dan menjaga farjinya..." Seterusnya ayat. "Dan katakanlah kepada orang-orang mukminat (wanita) supaya memejamkan penglihatannya dan menjaga farjinya ..." seterusnya ayat. (Alquran surat al-Nur ayat 30-31). Maka Majlis Tarjih telah memutuskan untuk memasang tabir atau sesamanya di dalam rapat-rapat atau pertemuan-pertemuan Persyarikatan Muhammadiyah, yang dihadiri oleh pria dan wanita guna mencegah terjadinya yang dilarang (diharamkan).

Akan tetapi dalam Keputusan Tarjih Sidoarjo dengan judul Masalah Hijab disebutkan: Setelah meninjau kembali keputusan Mu'tamar majlis Tarjih Muhammadiyah mengenai hukumnya "sitr" (tabir) dalam rapat-rapat Muhammadiyah yang dihadiri pria dan wanita, sebagaimana yang telah dimuat dalam kitab "Beberapa Masalah" (cetakan tahun 1964 bab 20 atau muka 300 di atas). Berdasarkan firman Allah dalam Alquran surat al-Nur ayat 30 dan 31 yang memberi pengertian bahwa pandang-memandang antara pria dan wanita lain (yang bukan muhrim atau bukan suami-isteri) tanpa hajat Syar'i, begitu pula pergaulan bebas antara pria dan wanita, dilarang oleh Islam, memutuskan: Tetap adanya hijab dalam rapat rapat persyarikatan Muhammadiyah yang dihadiri oleh pria dan wanita. Adapun cara pelaksanaannya diserahkan kepada yang bersangkutan dengan mengingat/ memperhatikan kondisi, waktu dan tempat. Keputusan ini mengganti putusan Majlis Tarjih Muhammadiyah yang sebelumnya.

Selanjutnya Majelis Tarjih memberikan penjelasan:

1. Hijab dimaksudkan: yang dapat menutup, menjaga pandangan antara pria dan wanita lain yang bukan muhrim dan atau bukan suami-isteri).

Hijab:

a. Boleh berujud tabir, apabila masih/ tetap dikhawatirkan saling tidak dapat menjaga diri masing-masing dari pandang memandang yang haram/terlarang.

b. Boleh tidak berujud tabir, apabila telah terjamin tidak akan ada pandang-memandang yang dikhawatirkan tersebut.

Jadi tidak diharuskan menghilangkan tabir dan tidak pula diharuskan memakai tabir. Hijab yang mana dari keduanya yang dijalankan/dipilih adalah menurut keyakinan/pendapat Muhammadiyah setempat.

2. Pengertian bahwa pandang memandang antara pria dan wanita lain (yang bukan muhrim atau bukan suami-isteri) tanpa hajat Syar'i begitu pula pergaulan bebas antara pria dan wanita dilarang oleh Islam", perlu kiranya dijelas-jelaskan kepada keluarga Muhammadiyah, besar kecil, tua muda, pria dan wanita dalam pertemuan-pertemuan, rapat-rapat, sidang-sidang dan pengajianpengajian serta dianjurkan/dididikkan dalam sekolah-sekolah (menurut keadaan dan 
tingkatan-tingkatannya), bahwa kita sekalian harus menjaga/mengikis percampuran, pergaulan, perhubungan bebas antara wanita dan pria, putera dan puteri yang sekiranya akan mengakibatkan dan memudahkan pandang-mamandang yang tidak diharapkan oleh agama.

Dengan demikian kita dapat memberikan tuntunan, bimbingan dan didikan baik kepada mereka dan dapat memberikan saluran yang baik untuk hidup, bekerja dan beramal dalam masyarakat yang kita bina bersama-sama dalam menuju masyarakat Islam yang sebenar-sebenarnya.

3. Dalam rapat-rapat persyarikatan Muhammadiyah yang dihadiri oleh pria dan wanita, berarti bahwa yang pokok/terutama ialah rapat-rapat, sidang-sidang, pertemuanpertemuan, termasuk pengajian-pengajian dan kursus-kursus yang diadakan oleh Muhammadiyah. Syukur selain Muhammadiyah mau mengikuti jejak yang baik itu.

4. Diserahkan kepada yang bersangkuatan, berarti terserah kepada kita (Muhammadiyah), menurut situasi dan kondisi setempat, bagaimana keyakinan/pendapat dari panitia/ penyelenggara, terutama Muhammadiyah setempat. Lebih baik lagi, jika Majlis/Lajnah Tarjih setempat yang menentukan dan memberikan petunjuknya.

\section{Budaya Lokal dalam Putusan Tarjih tentang Tabir}

Memperhatikan putusan tarjih yang terdapat dalam Kitab beberapa Masalah dan Keputsan Tarjih Sidoarjo, nampak ada dinamika dalam putusan tarjih. Keputusan Tarjih Sidoarjo menggantikan putusan tarjih sebelumnya. Walaupun demikian, belum nampak ada ketegasan dalam putusan tarjih Sidoarjo yang masih mengakomodir pemakaian tabir dan tidak memakai tabir dalam rapat-rapat atau pertemuan di persyarikatan. Kebolehan tidak memakai tabir setidaknya dapat diartikan sebagai akomodasi terhadap budaya lokal/setempat yang tidak memerlukan tabir dalam pertemuan.

Ungkapan yang digunakan dalam Kitab be- berapa Masalah adalah "memutuskan untuk memasang tabir", bukan mewajibkan memasang atau melarang tidak memasang. Sedangkan dalam putusan tarjih Sidoarjo dinyatakan "Tetap adanya hijab dalam rapat rapat persyarikatan Muhammadiyah yang dihadiri oleh pria dan wanita. Adapun cara pelaksanaannya diserahkan kepada yang bersangkutan dengan mengingat/ memperhatikan kondisi, waktu dan tempat". Putusan Sidoaarjo menggunakan istilah "hijab", menggantikan istilah tabir dalam putusan sebelumnya. Karena itu, istilah tabir diperjelas oleh majelis bisa berupa tabir atau tidak berupa tabir, dengan maksud menutup pandangan yang mendatangkan dosa bagilaki-laki dan perempuan dalam pertemuan yang diadakan. Disamping itu, putusan ini nampak bias karena ada pilihan yang diserahkan kepada yang bersangkuatan, kepada Muhammadiyah, menurut situasi dan kondisi setempat, bagaimana keyakinan/ pendapat dari panitia/penyelenggara, terutama Muhammadiyah setempat.

Ada beberapa kritik terhadap gerakan Muhammadiyah pada tataran implementasi, karena gerakan ini cenderung anti kebudayaan, tidak seperti yang diamanatkan oleh nilainilai yang ada di dalam keputusan organisasi. Penelitian Munir Mulkhan terhadap masyarakat petani di Kecamatan Wuluhan, Jember, Jawa Timur, menunjukkan bahwa Muhammadiyah belum memiliki konsep yang jitu dalam upaya mendorong perubahan dan kemajuan masyarakat dengan budaya populer (popular culture). Penelitian ini menghasilkan tipologi pengikut Muhammadiyah menjadi empat varian: Al-Ikhlas, Kyai Dablan, Munu (Muhammadiyah-NU), danMarmud(MarhenisMuhammadiyah). Varian Al-Ikhlas merupakan kelompok minoritas yang sangat puritan dan mengecam praktik TBC (Takhayul, Bid'ah, dan Khurafat). Meskipun sangat disegani karena kesalihannya, kelompok Al-Ikhlas tidak pernah mampu menduduki posisi penting di dalam keorganisasian tingkat kecamatan (cabang) dan desa (ranting). Sementara varian Kyai Dablan termasuk kelompok minoritas tetapi menguasai kepemimpinan dalam cabang dan ranting. Hal ini dikarenakan kelompok Kyai Dahlan sangat 
toleran terhadap praktik TBC meski tidak turut melakukan. Kelompok minoritas lainnya adalah Marmud yang tetap menjadikan TBC sebagai tradisi. Sementara kelompok mayoritas dalam pengikut Muhammadiyah di Wuluhan adalah Munu yang berprofesi sebagai petani dan tetap menjadikan TBC sebagai tradisi. ${ }^{3}$ Temuan ini jelas menunjukkan bahwa budaya populer yang sejak lama ditentang Muhammadiyah melalui dakwah terhadap TBC ternyata masih melekat pada sebagian pengikut Muhammadiyah, terutama yang berada di wilayah pedesaan.

Pernyataan bahwa Muhammadiyah adalah gerakan anti kebudayaan memang tidak cukup hanya dengan melihat apresiasinya terhadap budaya populer. Sebab, menurut definisi yang dikemukakan Taylor, kebudayaan secara umum adalah sebagai keseluruhan kompleksitas yang meliputi pengetahuan, keyakinan, seni, nilainilai moral, hukum, tradisi-tradisi sosial, serta seluruh kemampuan dan kebiasaan yang diperoleh manusia dalam kedudukannya sebagai anggota masyarakat (culture or civilization taken in its with ethno graphic sense, is that complex whole which includes knowledge, belief, art, morals, law, custom, and any other capabilities and habits acquired by man as a member of society). ${ }^{4}$ Pengertian ini menggambarkan betapa luas cakupan kebudayaan. Karena itu sangat tidak tepat jika dikatakan Muhammadiyah adalah gerakan anti kebudayaan. Kuntowijoyo mengistilahkan Muhammadiyah merupakan gerakan kebudayaan baru tanpa kebudayaan lama. ${ }^{5}$

Oleh sebab itu, sebagai konsekuensi dari perumusan kerangka metodologis dialektika agama dan budaya lokal, Muhammadiyah harus menggagas dua hal penting. Pertama, otonomi dan desentralisasi pemikiran keagamaan dalam konteks budaya lokal. Kedua, membuka ruang selebar-lebarnya untuk menampung pluralitas

\footnotetext{
${ }^{3}$ Abdul Munir Mulkhan, Islam Murni dalam Masyarakat Petani, (Yogyakarta: Bentang, 2005), h. 350.

${ }^{4}$ Edward B. Taylor, "Culture," dalam David L. Shills (ed.), International Encyclopedia of the Social Sciences, vol. 3, (New York: The Macmillan Company and the Free Press, 1996), h. 527.

5 Kuntowijoyo, Muslim Tanpa Masjid: Esai-esai Agama, Budaya, dan Politik dalam Bingkai Strukturalisme Transendental, (Bandung: Mizan, 2001), h. 159.
}

pemikiran keagamaan. Ini merupakan langkah baru--untuk tidak mengatakan revolusi--sebuah konvensi organisasi raksasa yang lazimnya terkelola secara sentralistik.

Dalam kaitan budaya lokal, Muhammadiyah harus menerapkan suatu kebijakan desentralisasi wacana dan fatwa dalam hierarki kelembagaan organisasi. Artinya, pluralitas budaya lokal tidak dapat dijawab oleh pemikiran keagamaan yang berorientasi top down-menanti fatwa dan petunjuk lembaga Majelis Tarjih dan Pengembangan Pemikiran Islam di tingkat pusat. Karena, keragaman budaya itu sendiri adalah masalah nyata yang dihadapi pada tingkat lokal. Dengan kebijakan ini, dimungkinkan lahir wacana dan fatwa keagamaan yang plural sesuai dialektika ruang dan waktu, yang pada gilirannya dapat memperkaya khazanah pemikiran keislaman lokal yang variatif, kreatif, dan inovatif.

Desentralisasi, juga merangsang elite Muhammadiyah untuk bersikap kritis dan kreatif terhadap persoalan-persoalan yang terjadi di daerah/ wilayahnya masing-masing. Risikonya adalah terhadap masalah yang sama, fatwa-fatwa sosialkeagamaan dan cara penerapannya antara daerah satu dengan yang lain bisa jadi berbeda, berdasarkan kultur dan tradisi masing-masing.

Desentralisasi menuntut Muhammadiyah untuk segera mengurangi manajemen sentralistiknya. Paling tidak, organisasi harus menebarkan semangat independensi dan menghilangkan ketergantungan secara birokratis terhadap level pimpinan di atasnya. Masing-masing Pimpinan Wilayah dan Daerah diberi kebebasan untuk mengembangkan amal usahanya tanpa harus dibatasi "buku petunjuk pelaksanaan" dengan administrasi yang berbelit-belit dari Pimpinan Pusat.

Selain desentralisasi, Muhammadiyah juga harus membuka ruang lebar bagi keragaman pemikiran. Alasannya, kebesaran dan keberlimpahan SDM dalam Muhammadiyah berlanjut pada keragaman pemikiran keagamaan. Sekurangnya ada tiga arus pemikiran dominan dalam organisasi berbasis masyarakat urban ini.

Pertama, arus pemikiran keagamaan rasionalhumanis. Kelompok ini selalu menyerukan agar Muhammadiyah jangan sekali-kali terjebak 
pada pemahaman keagamaan yang sempit, doktrinal, dan rigid. Pemahaman keagamaan dalam Muhammadiyah harus selalu berbasis pada konteks perkembangan zaman yang menyertainya. Segala upaya perumusan dan segenap produk pemikiran keagamaan tidak boleh meninggalkan peran serta ilmu-ilmu sosial dan humaniora, seperti sosiologi, psikologi, filsafat, budaya, dan lain-lain. Dengan kata lain, dialektika antara normativitas wahyu dengan historisitas pemahaman tidak boleh berhenti bila Muhammadiyah tidak ingin mengalami pembusukan pemikiran dari dalam.

Kedua, arus pemikiran keagamaan bercorak spiritual/mistis. Wacana spiritualitas ini dimotori aktivis mudanya. Bahkan, gerakan tasawuf/ spiritualitas kini merambah tataran praktis sebagaimana terjadi di kampus-kampus Muhammadiyah. Di Universitas Muhammadiyah Surakarta (salah satu dari empat perguruan tinggi Muhammadiyah terbesar) diselenggarakan pengajian tasawuf bernama Noto Ati (Menata Hati) yang dibimbing seorang guru sufi. Pengajian rutin setiap hari Rabu ini selalu dipenuhi peserta dari kalangan mahasiswa, karyawan, dan dosen.

Wacana spiritualitas di Muhammadiyah melahirkan liberalisme pemikiran dan pengamalan Islam yang justru masuk ke dalam jantung agama (the heart of religion), sehingga perbedaan agama-agama yang bersifat formal tidak lagi dianggap penting. "Setiap agama adalah jalan yang benar menuju Tuhan, karena itu klaim kebenaran agama hanya akan mempersempit makna agama itu sendiri”.

Ketiga, selain kedua arus itu, sikap keberagamaan formalisme-skriptural juga kian merebak di kalangan warga Muhammadiyah. Gejala ini merupakan reaksi terhadap "rutinisasi teologis".

Kembali mengenai tabir dalam pertemuan laki-laki dan wanita, tanggal 21 Januari 1939 kantor berita ANTARA mewawancarai Soekarno perihal dirinya bergegas pergi meninggalkan rapat umum Muhammadiyah yang sedang berjalan sebagai protes penggunaan "tabir".

Mantan presiden I RI tersebut menganggap tabir adalah suatu simbol perbudakan perempuan. Ia berkeyakinan bahwa Islam tidak mewajibkan tabir itu. Islam memang tidak mau memperbudak perempuan, sebaliknya Islam ingin mengangkat harkat, martabat, dan derajat perempuan. Tabir adalah suatu contoh yang tidak diperintahkan oleh Islam, tetapi diadakan oleh umat Islam.

Sebelumnya, Soekarno sudah memperingatkan kepada pengurus organisasi Islam kedua terbesar itu untuk meniadakan tabir di dalam rapat tersebut. Jika tidak, ia tak mau datang, dan seluruh pengurus menyetujui secara mufakat tentang hal tersebut. Namun, ada beberapa pengurus yang tidak sepaham dengannya memasang tanpa diketahui oleh pengurus lain. Soekarno tidak marah terhadap sesuatu adat yang kolot, dan orang-orang yang tidak sepaham dengannya. Baginya, saudarasaudaranya tidak sengaja mau menghina kaum perempuan, mereka merdeka dalam keyakinannya. Sepertinya soal kecil, selembar kain panjang yang remeh, tetapi hakekatnya sangat besar dan sangat penting mengenai posisi sosial kaum perempuan di mata lelaki.

Soekarno tidak hanya menolak penindasan dan perbudakan dalam ajaran Marxisme, tetapi ia juga kerap menolak hukum agama yang tidak diperintahkan oleh Tuhan dan rasul-Nya. Tabir adalah simbol dari perbudakan kaum perempuan! Meniadakan perbudakan adalah salah satu tugas sejarah.

Tidakkah Islam melarang lelaki dan perempuan berpandangan satu sama lain. Islam pada batinnya menyuruh lelaki/pria dan perempuan (pada umumnya) menundukkan mata, jika berhadapan satu sama lain. Tetapi boleh jadi tabir itu dianggap oleh sebagian umat Islam sebagai suatu alat, agar lelaki dan perempuan tidak berpandangan satu sama lain. Sebab sangat nyata pada umumnya, berpandangpandangan satu sama lain itu terlarang. Boleh jadi seperti itu, tetapi itu satu ikhtiar di luar perintah Tuhan, dan ganjil menurut visi Soekarno tentang agamanya.

Sedianya "Tabir" biasa digunakan oleh sebagian umat Islam dengan memisahkan antara pria dan wanita dengan menggunakan kain penutup sebagai tanda, ketika mengadakan kegiatan ritual keagamaan/acara organisasi. Hal itu bisa saja terbukti benar! 
Sebagai ilustrasi, Tuhan sangat melarang manusia untuk mencuri, tetapi kenapa tidak semua rumah ditutup rapat-rapat, agar orang lain tidak dapat mencuri? Atau Tuhan melarang manusia untuk berbohong/berdusta tetapi, kenapa kita yang beragama Islam tidak menjahit saja mulut kita, agar kita umat Islam tidak melakukan kebohongan/dusta. Artinya, dengan pandangmemandang antara lelaki dan perempuan dilarang bila tidak perlu, tetapi tidak diperintahkan untuk menggunakan tabir. Masing-masing orang harus menjaga hati dan matanya sendiri.

Bagaimana menempatkan seorang lelaki dan perempuan di tempat rapat, atau pun tempat ibadah. Soekarno lantas menjawabnya dengan mengatakan, saya anti pergaulan Barat yang imperialis. Maka, berikanlah jarak antara lelaki dan perempuan. Satu pihak ditempatkan pada bagian depan, dan satu lagi pada bagian belakang, seperti yang dicontohkan sang nabi.

Soekarno masuk Muhammdiyah bukan berarti ia menyetujui semua hal yang ada di dalam organisasi tersebut. Di Muhammadiyah banyak hal/elemen yang masih berpegang teguh kolot sekali. Ia mangatakan, ingin mengabdi kepada agamanya, yaitu Islam. Tetapi tidak semua sepak terjang dunia Muhammadiyah ia sepakati.

Seorang Soekarno ingin menjadi motor evolusi dunia Islam. Sejarah dunia menunjukkan bahwa selamanya akan ada perjuangan dan dialektika antara kuno dan muda, antara ortodok dan evolusi, antara kolot dan modern. Islam sejati seyogyanya harus mengangkat derajat kaum perempuan, akan tetapi sikap ortodok/keras kepala/konservatif/ puritan menjadi rem besar bagi sebuah evolusi kaum perempuan. Contoh nabi Muhammad, dari zaman jahiliyah menjadi zaman terang benderang, atau Bapak Republik Turki, Kemal Attaturk yang membawa Turki ke arah zaman modern dari sifat kuno dan kolot.

Haji Agus Salim, seorang pahlawan kemerdekaan pernah merobek "tabir" di salah satu rapat umum secara terang-terangan di hadapan pengunjung yang hadir. Dalam pandangan Soekarno, perbuatan seperti yang dicontohkan H. Agus Salim adalah suatu perbuatan mulia yang harus mempunyai keberanian moril yang besar.

\section{Penutup}

Demikian pembahasan tentang Tabir dalam Putusan Tarjih Muhammadiyah yang sedikit banyaknya sudah menampakkan keinginan usaha mengakomodasi budaya lokal di mana putusan itu diterapkan. Akomodasi ini secara tekstual, putusannya dinilai masih malu-malu, akan tetapi di lapangan secara umum sudah menyesuaikan dengan budaya setempat atau bahkan dengan kemajuan peradaban.

\section{Pustaka Acuan}

Bakry, M. Natsir, Peranan Lajnah Tarjih Muhammadiyah, Jakarta: C.V. Karya Indah, 1985, Cet. ke-1.

Berita Resmi Muhammadiyah, Nomor Khusus, "Tanfidz Keputusan Muktamar Tarjih Muammadiyah XXII", P.P. Muhammadiyah, 1990.

Dasuki, Hafizh dkk., Ensiklopedi Hukum Islam, Jakarta: P.T. Intermasa, 1977, Cet. ke-1.

Djamil, Fathurrahman, Metode Ijtihad Majelis Tarjih Muhammadiyah, Jakarta: Logos Publishing House, Cet. ke-1, 1990.

Khalaf, Abd al-Wahhab, Khulashah Tarikh Tasyri' al-Islamy, Jakarta: al-Majlis A'la al-Indonesia li al-Da'wah al-Islamiyyah, t.th., Cet. ke-8.

Kuntowijoyo, Muslim Tanpa Masjid: Esai-esai Agama, Budaya, dan Politik dalam Bingkai Strukturalisme Transendental, Bandung: Mizan, 2001.

Muhammadiyah, Majlis Tarjih, "Pembinaan Hukum Fiqh di Bidang Muamalat", Suara Muhammadiyah, I, 15 Juli 1965.

Muhammadiyah, PP., Himpunan Putusan Tarjih, Yogyakarta: Persatuan, t.th. Cet. ke-3.

Mulkhan, Abdul Munir, Islam Murni dalam Masyarakat Petani, Yogyakarta: Bentang, 2005.

Nashir, Haedar dkk, Materi Induk Pengkaderan Muhammadiyah, Yogyakarta: BPK Pimpinan Pusat Muhammadiyah, 1994.

Taylor, Edward B., "Culture," dalam David L. Shills (ed.), International Encyclopedia of the Social Sciences, vol. 3, New York: The Macmillan Company and the Free Press, 1996. 